\title{
Endoscopic Transnasal Odontoidectomy
}

\author{
Cesare Zoia1ำ Daniele Bongetta ${ }^{2,3}$ Sabino Luzzi ${ }^{1,2}$ \\ ${ }^{1}$ Neurosurgery Unit, Fondazione IRCCS Policlinico San Matteo, \\ Pavia, Italy \\ 2 Neurosurgery Unit, Department of Clinical-Surgical, Diagnostic and \\ Pediatric Sciences, Università degli Studi di Pavia, Pavia, Italy \\ ${ }^{3}$ Neurosurgery Unit, Ospedale Fatebenefratelli e Oftalmico, ASST \\ Fatebenefratelli Sacco, Piazzale Principessa, Milano, Italy
}

\begin{abstract}
Address for correspondence Cesare Zoia, MD, PhD, Neurosurgery Unit, Fondazione IRCCS Policlinico San Matteo, viale Golgi 19, 27100 , Pavia, Italy (e-mail: gioiaoffice@gmail.com).
\end{abstract}

J Neurol Surg B 2021;82(suppl S1):S10-S11.

\begin{abstract}
Keywords

- odontoidectomy

- endoscopic transnasal surgery

- endoscopic cervical decompression

- craniovertebral junction

Background Odontoidectomy may represent the treatment of choice for symptomatic ventral craniovertebral junction stenosis in selected cases. An endoscopic transnasal approach has been proposed as an alternative to a classic transoral approach. Method We report a case of a patient with a craniovertebral junction stenosis due to the ossification of the posterior ligament. The clinical and radiological records of the patient and a step-by-step description of the surgical technique are presented (-Fig. 1). Conclusion Endoscopic transnasal odontoidectomy provides a direct access to the dens and adjacent structures of the anterior upper cervical spine with a less invasive burden on the oropharingeal structures.

The link to the video can be found at: https://youtu.be/Ofrk1sFTV9I.
\end{abstract}

Conflict of Interest

None declared.

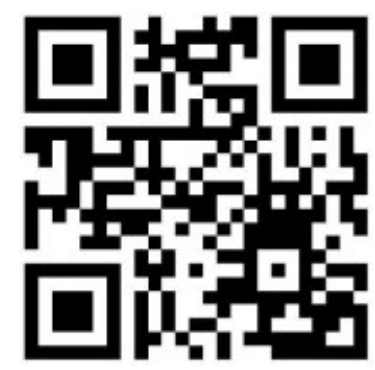

received

January 10, 2019

accepted

March 8, 2020

published online

November 23, 2020 www.thieme.com/skullbasevideos

www.thieme.com/jnlsbvideos

(c) 2020. The Author(s).

This is an open access article published by Thieme under the terms of the Creative Commons Attribution-NonDerivative-NonCommercial-License, permitting copying and reproduction so long as the original work is given appropriate credit. Contents may not be used for commercial purposes, or adapted, remixed, transformed or built upon. (https://creativecommons.org/ licenses/by-nc-nd/4.0/)

Georg Thieme Verlag KG, Rüdigerstraße 14, 70469 Stuttgart, Germany 

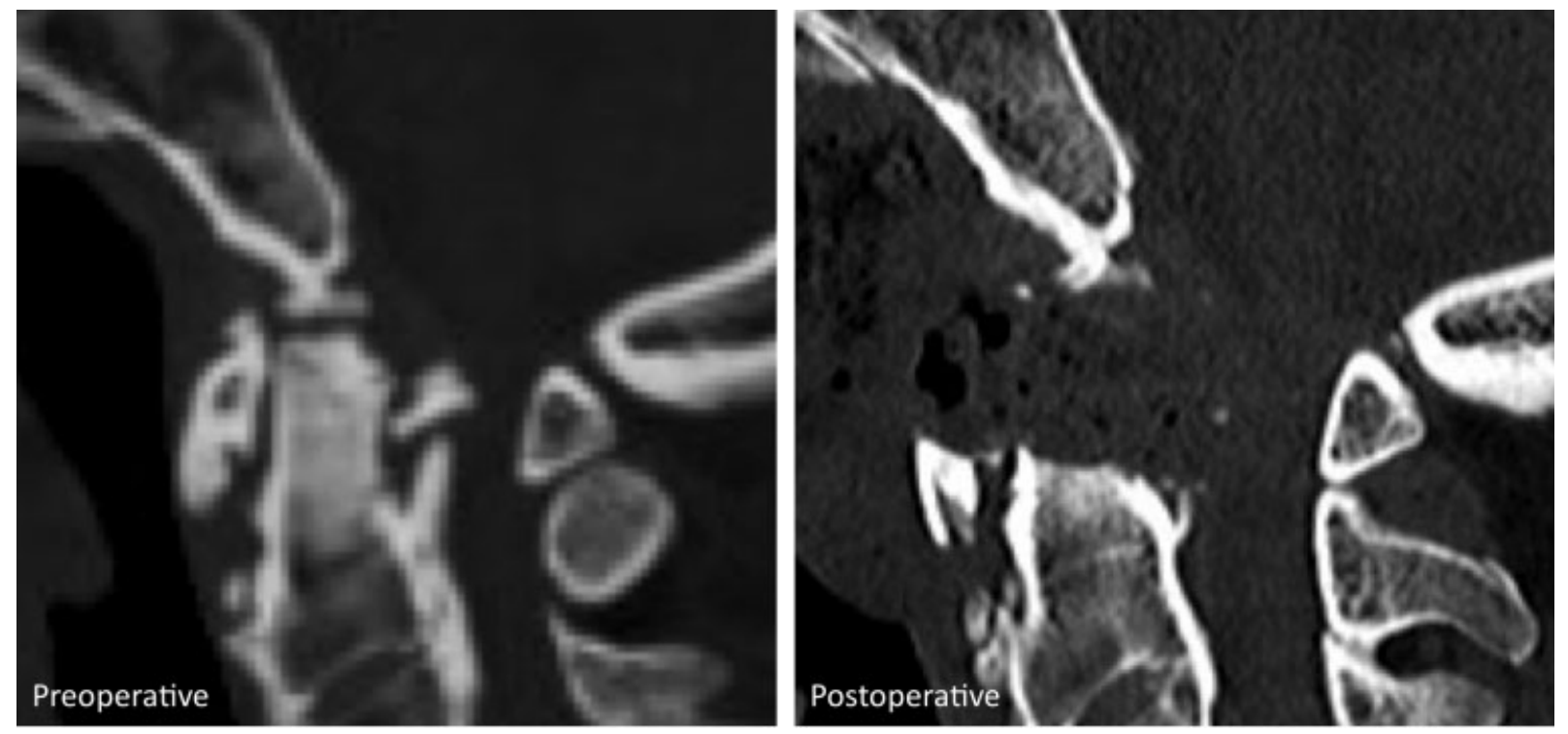

Fig. 1 Pre- and postoperative sagittal CT. 